\title{
Microarchitectural and Mechanical Characterization of Sickle Bone
}

Mykel Green ${ }^{1}$, Idowu Akinsami ${ }^{2}$, Angela Lin $^{3}$, Shereka Banton ${ }^{2}$, Samit Ghosh ${ }^{4}$, Binbin Chen ${ }^{2}$, Manu Platt ${ }^{2}$, Ifeyinwa Osunkwo ${ }^{5}$, Solomon Ofori-Acquah ${ }^{4}$, Robert Guldberg ${ }^{3}$, and Gilda Barabino $^{1,2^{*}}$

1. Department of Biomedical Engineering, The City College of New York, New York, NY, 10031, USA

2. Wallace H. Coulter Biomedical Engineering, Georgia Institute of Technology, Atlanta, GA 30332, USA

3. Parker H. Petit Institute for Bioengineering and Bioscience, Georgia Institute of Technology, Atlanta, GA 30332, USA

4. Vascular Medicine Institute, University of Pittsburgh School of Medicine, Pittsburgh, PA 15261, USA

5. Levine Cancer Institute, Carolinas HealthCare System, Charlotte, NC 28204, USA

*Corresponding Author: E-mail address: gbarabino@ccny.cuny.edu

\section{$\underline{\text { Abstract }}$}

Individuals with sickle cell disease often experience acute and chronic bone pain due to occlusive events within the tissue vasculature that result in ischemia, necrosis, and organ degeneration. Macroscopically, sickle bone is identified in clinical radiographs by its reduced mineral density, widening of the marrow cavity, and thinning of the cortical bone due to the elevated erythroid hyperplasia accompanying the disease. However, the microstructural architecture of sickle bone and its role in mechanical functionality is largely unknown. This study utilized micro-CT and biomechanical testing to determine the relationship between the bone morphology, tissue mineral density, and trabecular and cortical microarchitecture of 10and 21-week-old femurs from transgenic sickle male mice and littermates with sickle trait, as well as a wild-type control. While bone tissue mineral density did not vary among the genotypes at either age, variation in bone microstructure were observed. At 10 weeks, healthy and trait mice exhibited similar morphology within the cortical and trabecular bone, while sickle mice exhibited highly connected trabeculae. Within older femurs, sickle and trait specimens displayed

\section{$\underline{\text { Abbreviations }}$}

SCD, Sickle Cell Disease; SS, homozygous recessive sickle cell disease; AS, heterozygous sickle trait; AA, wild-type control. 
significantly fewer trabeculae, and the remaining trabeculae had a more deteriorated geometry based on the structure model index. Thinning of the cortical region in sickle femurs contributed to the displayed flexibility with a significantly lower elastic modulus than the controls at both 10- and 21-weeks old. Wild-type and trait femurs generally demonstrated similar mechanical properties; however, trait femurs had a significantly higher modulus than sickle and wild-type control at 21-weeks. Overall, these data indicate that the progressive damage to the microvasculature caused by sickle cell disease, results in deleterious structural changes in the bone tissue's microarchitecture and mechanics.

\section{$\underline{\text { Key Words }}$}

Sickle Cell Disease; Microarchitecture; Biomechanics; Micro-CT; Bone.

\section{Introduction}

Microvascular vaso-occlusion experienced by individuals living with sickle cell disease (SCD) is one of the most common reasons for hospitalization [Almedia and Roberts, 2010; Enjindu et al., 2007]. These painful crises spontaneously manifest throughout the patient's life and are most frequently reported to be localized in the bone [Chiang and Frenette, 2005]. Under normal circumstances, red bone marrow, the site of hematopoiesis, is temporarily present throughout the skeleton until it is replaced by yellow, or fatty, marrow in the peripheral bones. However, sickle patients exhibit erythropoietic hyperplasia resulting in the maintenance of and reconversion to red marrow [Mankad et al., 1990]. Moreover, marrow infarctions due to crises occur more frequently in the red marrow than in yellow [Rao et al., 1989].

Infarcts within bone are considered clinically silent and tend to be discovered incidentally by conventional radiological scans, such as monochromatic x-rays [Ware et al., 1991]. The hypoxic nature of the bone marrow microenvironment promotes erythrocyte sickling and 
necrosis [Smith, 1996]. Collectively, infarcts and bone marrow expansion in the long bones of sickle patients contributes to cortical bone thinning and increasing of trabecular spacing, which may consequently expedite the deterioration of the bone's mechanical strength [Serjeant and Serjeant, 2001]. Albeit an under investigated aspect of SCD, nearly 30\% of adult sickle patients self-reported multiple fractures due to low impact trauma in various locations, including the vertebrae, wrist, metatarsal, and femoral bones [Arlet et al. 2013]. Multiple fractures have also been reported in children with sickle cell disease as young as 19 months [Omer et al., 2013] and may continue to occur throughout adolescents, sometimes accompanied with osteomyelitis [Ebong, 1986].

Phenotypically, these observed changes in sickle bone closely resemble osteoporotic bone, from which it became standard clinical practice to utilize bone mineral density (BMD) levels obtained from dual-energy X-ray absorptiometry (DXA) to monitor bone health and predict fracture risk [Brinker et al., 1998; World Health Organization, 1994]. However, the unreliable interpretations of DXA results have led to numerous misdiagnoses due to overestimating and underestimating BMD levels in general [Gafni and Baron, 2004; Wren et al., 2005]. Additionally, variations in the BMD of sickle patients are based on age, gender, and ethnicity, further minimizing the usefulness of BMD to monitor sickle bone by itself [Almedia and Roberts, 2005; Gupta et al., 2009; Lal et al., 2006; Sarrai et al., 2007].

The utilization of microcomputed tomography (micro-CT) provides a platform for the fabrication of high resolution 3D images of the bone microenvironment in a non-destructive and time-lapsed fashion, furthering the ability to quantitatively assess bone quality [Bouxsein et al., 2010]. The unique microarchitecture of the trabecular regions influences whole bone strength, yielding various mechanical properties dependent on quality and organization of the bone 
[Gibson, 1985; Turner et al., 1990; Ulrich et al., 1997]. Unlike DXA, micro-CT determines the tissue mineral density (TMD) of the mineralized bone tissue only, which directly influences clinical BMD measurements but negates the attenuation of soft tissue (muscle, bone marrow, etc.) that may complicate interpretations. Currently, high resolution clinical micro-CT technology is limited only to the extremity regions of the body; however the use of animal models with micro-CT serves as critical tool for investigating human pathology [Wang et al., 2005]. In lieu of such technological advancements and established knowledge, the bone phenotype in SCD has yet to be characterized beyond monochromatic x-rays.

To further examine the effects of SCD in bone, we performed micro-CT image analyses to elucidate TMD and the microarchitecture of trabecular and cortical bone of femurs collected from transgenic SCD (SS) mice and littermates with sickle trait (AS), as well as mice expressing normal human hemoglobin (AA). Femurs were collected at 10 and 21 weeks of age for image analyses as well as biomechanical testing to determine the mechanical properties respective to femur morphology. Our data demonstrate that TMD does not differ significantly between these three groups of mice. However, we found that differences in microarchitecture contribute to the unique mechanical properties of sickle bone.

\section{Materials and Methods}

\subsection{Experimental Animals}

In order to characterize the sickle bone phenotype, we employed a Townes transgenic sickle mouse model and C57BL/6 wild-type controls [Ghosh et al., 2012; Ryan et al., 1997]. Mice were selectively mated and categorized into either homozygous (SS) or heterozygous (AS) expression as determined by PCR. Analysis using micro-CT and biomechanical testing was conducted on 
femurs were harvested without chemical fixation from 10- and 21-week-old male mice and stored frozen at $-20^{\circ} \mathrm{C}$ wrapped in phosphate buffer saline soaked gauze until time of analysis (n = 3-6/group). All protocols were IACUC approved by Emory University and Georgia Institute of Technology.

\subsection{Microcomputed Tomography}

The trabecular and cortical bone morphologies of femurs were examined by micro-CT imaging ( $\mu$ CT 40, Scanco Medical, SUI), as previously reported [Robertson et al., 2006]. Morphological and mineral density analyses were conducted on the femoral, cortical, and trabecular regions scanned at a voxel size of $12 \mu \mathrm{m}$ (Fig. 1, shaded areas). Two regions of the distal femur were evaluated - one region in the epiphysis $(0.32 \mathrm{~mm}$ in length distal of the growth plate) and one region in the metaphysis (extended $0.80 \mathrm{~mm}$ towards the diaphysis from an initial point $0.05 \mathrm{~mm}$ proximal to the growth plate). Within these regions, trabecular and cortical bone were first spatially segmented using an auto-contouring program, then each volume was manually checked and adjusted to ensure consistent boundary properties. For the diaphyseal region, cortical bone geometry and morphology were evaluated in a $1.0 \mathrm{~mm}$ mid-diaphyseal scan, which corresponded with the area tested in four-point bending (Fig. 1) [Buie et al., 2007]. Distinction between mineralized and soft tissue within the metaphyseal, epiphyseal, and diaphyseal regions was maintained by global thresholds of 155,162 , and 205 , with representative hydroxyapatite equivalents of 558,592 , and $799 \mathrm{mg} / \mathrm{cm}$ respectively.

\subsection{Analysis of bone morphology and microarchitecture}

Morphometric analyses of trabecular and cortical bone followed previously established direct distance transformation algorithms within the Scanco evaluation software [Hildebrand and 
Rüegsegger, 1997; Robertson et al., 2006]. We reported trabecular spacing (Tb.Sp.), trabecular thickness (Tb. Th.), trabecular number (Tb.N.), trabecular connectivity density (Conn.D), bone volume (BV), total volume (TV), bone volume fraction (BV/TV), and structure model index (SMI), as well as the cortical bone area (BA), total area (TA), cortical bone area fraction (BA/TA), cortical thickness (Cort.Th.), and moment of inertia around the medial lateral axis $\left(\mathrm{I}_{\mathrm{ML}}\right)$.

\subsection{Analysis of tissue mineral density}

Bone tissue mineral density was determined from the regions scanned by micro-CT. A series of hydroxyapatite (HA) phantoms with known densities were used to calibrate the system. MicroCT data were converted into true mineral density values $\left(\mathrm{mg} \mathrm{HA} / \mathrm{cm}^{3}\right)$ from a standard linear attenuation curve. Average mineral density values across all thresholded bone voxels in the specified volume of interest were reported.

\subsection{Mechanical testing via four-point bending}

Femoral mechanical properties were measured via four-point bending with a MTS 858 Mini Bionix (Eden Prairie, MN) mechanical testing system as previously reported [Robertson et al., 2007]. Briefly, thawed femurs were placed on support pins spaced $6.2 \mathrm{~mm}$ wide with radius of curvature $0.5 \mathrm{~mm}$ while a load was applied at a rate of $0.05 \mathrm{~mm} / \mathrm{s}$ until failure (Fig. 1). Femurs were tested in the anterior-posterior plane where the upper pins were centered on posterior side of the mid-diaphyseal location scanned by micro-CT. The force and deflection data obtained from the MTS system were used to calculate stiffness, yield force, post yield deflection (PYD), and work to failure. The yield point was defined with a $10 \%$ reduction of secant slope from the linear region of the force-deflection curve. The force-deflection data were normalized using the 
moment of inertia data obtained from the micro-CT analyses to calculate stress $(\sigma)$ and elastic modulus (E) with equations (1) and (2), respectively; where $\mathrm{F}=$ applied force, $\mathrm{c}=1 / 2$ of anterior-posterior axis, $\mathrm{a}=$ horizontal distance between upper and lower supports $(2 \mathrm{~mm}), \mathrm{I}_{\mathrm{ML}}=$ 2nd moment of area about the medial-lateral axis, $\mathrm{S}=$ stiffness, $\mathrm{L}=$ horizontal distance between upper and lower supports $(6.2 \mathrm{~mm})$.

(1) $\sigma=\mathrm{F}\left(\mathrm{ac} / 2 \mathrm{I}_{\mathrm{ML}}\right)$

(2) $\mathrm{E}=\mathrm{S}\left(\mathrm{a}^{2} / 12 \mathrm{I}_{\mathrm{ML}}\right)(3 \mathrm{~L}-4 \mathrm{a})$

\subsection{Statistical analysis}

Data were analyzed by analysis of variance (ANOVA) tests with post-hoc t-test for pairwise comparison either between genotypes or age. All data are represented as mean \pm standard error of mean (SEM). A p-value $<0.05$ was considered statistically significant.

\section{Results}

\subsection{Bone Tissue Mineral Density}

Femoral cortical and trabecular TMD were measured with micro-CT. TMD did not differ significantly between AA, AS, or SS at either 10 or 21 weeks of age, as determined by ANOVA (Table 1). Overall, at 21 weeks TMD was as much as $10 \%$ higher for some regions of analysis at 10 weeks among the three groups. However, the metaphysis in SS bone did not have as much of an increase in TMD when compared to AA and AS.

\subsection{Mid-Diaphyseal Cortical Geometry}

At the mid-diaphysis, the total area did not differ between the three groups at 10 weeks of age; however, AA femurs exhibited significantly larger areas of mineralized tissue compared to AS 
and SS femurs $(\mathrm{p}<0.05)$ (Table 2). Although the total area increased with age among the genotypes, the amount of mineralized tissue present was reduced as much as $27 \%$ in the AS and SS femurs than in the AA mouse $(\mathrm{p}<0.05)$. Moreover, SS femurs exhibited a significantly lower areal fraction of cortical bone compared to AA and AS at 10- and 21-weeks due to maintenance of a relatively smaller area of mineralized bone while displaying as much as a $10 \%$ increase in total area with maturation $(\mathrm{p}<0.05)($ Fig. 2A). At 10 and 21 weeks, average cortical thickness was significantly thinner in SS bone than the AA control and AS $(\mathrm{p}<0.05)$. Qualitative differences were noticed in endosteal and periosteal shape at the mid-diaphysis, with SS femurs displaying more balanced thinning of the cortical area (Fig. 3).

\subsection{Trabecular Bone Microarchitecture}

Within the trabecular metaphyseal and epiphyseal regions, there were no differences in BV/TV amongst the genotypes for younger animals (Fig. 2B \& 2C). Older animals exhibited a universal reduction in the percentage of total volume occupied by mineralized tissue in all specimens except the AA epiphyseal region $(\mathrm{p}<0.05)$. In comparison to AA and AS, SS bone occupied significantly less bone volume in the trabecular regions $(\mathrm{p}<0.05)$.

Trabecular number, thickness, spacing, connectivity density, and SMI were characterized within the distal femoral epiphysis and metaphysis of AA, AS, and SS mice at 10 and 21 weeks of age (Table 3). Qualitative observations from micro-CT images of trabecular regions suggested thinner trabeculae for SS (for both regions and both ages) as well as greater trabecular spacing in the metaphysis of AS and SS mice at 21 weeks (Fig. 4). Quantitative analyses of Tb.Th. confirmed significant difference for SS compared to AA in the epiphysis but not metaphysis at 21 weeks of age $(\mathrm{p}<0.05)$. Significant increases measured for Tb.Sp. in the metaphysis with 
maturation agreed with previous observations of SS bones having greater trabecular spacing (Table 3). Additionally, micro-CT analyses revealed that specifically within the metaphyseal region, AS and SS femurs exhibited significantly lower Tb.N. than AA controls at 21 weeks of age $(\mathrm{p}<0.05)$. At 10 weeks, the difference in interconnectivity of the trabecular regions of the different genotypes was negligible (Table 3, Fig. 5). At 21 weeks epiphyseal connectivity density showed a universal reduction with respect to age but no significant difference across genotypes, while a reduction of up to $80 \%$ was observed in SS and AS metaphyseal connectivity density compared to the AA control $(\mathrm{p}<0.05)$ (Table 3, Fig. 5B). SS femurs also exhibited significant deterioration of connectivity density among individual genotypes with respect to age, in which epiphyseal and metaphyseal regions were reduced by $30 \%$ and $90 \%$ respectively $(\mathrm{p}<0.05)$. Trabecular SMI was also measured, in which the geometry of trabeculae was characterized as either "plate-like" or "rod-like," represented within a scale of 0 to 3, respectively. All genotypes underwent a progression toward more rod-like trabeculae with age (Table 3). Notably, SS trabeculae showed a significantly larger transition toward a higher SMI than AA and AS controls in the metaphyseal region $(\mathrm{p}<0.05)$.

\subsection{Biomechanical Properties}

Femurs were evaluated via four-point bending to determine the mechanical properties relative to genotype and age (Table 4, Fig. 6). At 10 weeks, maximum force, yield force, work to failure, ultimate stress, and yield stress were comparable across genotypes. At 21 weeks, AA and AS displayed similar thresholds for yield and maximum forces and stresses, while, SS bones could only withstand approximately $40 \%$ less force and stress than AA and AS ( $<<0.05)$. Additionally, SS femurs deformed with a significantly lower yielding force at 21 weeks than at 10 weeks in comparison to the other genotypes that required relatively similar forces $(\mathrm{p}<0.05)$. 
The PYD for AS and SS bone at 10 weeks-of-age were significantly larger than the AA control; however, the PYD between genotypes did not differ with maturation $(\mathrm{p}<0.05)$. The work required for the femurs to fail, which is associated with PYD, remained relatively similar among genotypes at both ages. SS femora were significantly less stiff and demonstrated a lower elastic modulus than AA and AS at 10 and 21 weeks-of-age $(\mathrm{p}<0.05)$. Furthermore, the femoral elastic modulus tended to decrease with maturation for AA and SS specimens; however, the 21 week old AS femora had a significantly larger modulus $(\mathrm{p}<0.05)$.

\section{Discussion}

The pathology of SCD disturbs the metabolic activity and damages the structural integrity of tissues throughout the body, resulting in sporadic and acute pain most commonly affecting bone and joints [Aguilar et al., 2005]. Through conventional radiology, it is widely accepted that SCD in bone results in widening of the bone marrow cavity, along with a decrease in bone thickness and mineral content; however, the morphology of sickle bone at the microscale and its contribution mechanically is still largely uncharacterized [Almeida and Roberts, 2005]. In order to gain further insight into how SCD and age affects bone, we examined their influence on the bone mineral density, morphology, and mechanical properties at cortical and trabecular regions of the femoral bone in a transgenic mouse model.

Whole bone strength is based on the combination of material properties (such as mineralization and extracellular matrix composition) [Burstein et al., 1975], microarchitecture [Galante et al., 1970; Ulrich et al., 1997], and total mass (bone volume) [Carter and Hayes, 1977]. TMD was not significantly different among the sickle and control animals within the same age groups. This observation was contrary to clinical observations in which more than half 
of the pediatric and adult patients with SCD have low BMD, and may be due to the measuring of TMD or the utilization of a non-human model [Brinker et al., 1998; Fung et al., 2008b; Lal et al., 2006; Miller et al., 2006]. However, previous studies have shown that healthy bone samples of different ages with the same TMD have variations in mechanical strengths due to different cortical and trabecular architectures [Galante et al., 1970; Ulrich et al., 1997]. Bonnet et al., suggest that cortical thickness primarily contributes to the breaking force necessary while performing bending analysis [Bonnet et al., 2006]. This finding supports the relatively similar mechanical forces demonstrated between genotypes in the younger femurs (with similar cortical area and thickness) as opposed to the nearly $40 \%$ reduction in forces necessary to deform and fracture older sickle bone (with diminished cortical bone area and thickness). Additionally, fourpoint bending generates compressive and tensile data that are not influenced by the load placed on specific sites of fragility, but rather the distribution of the load throughout the cortical and trabecular regions [Brodt et al. 1999; Turner and Burr, 1993].

It has been previously reported that, with age, trabecular bone in men becomes fragile due to trabecular thinning while women suffer from loss of trabecular plates [Aaron et al., 1987]. However, micro-CT analyses of sickle mouse femora suggested that SCD further confounds the natural deterioration of the trabeculae. The signature sickle bone characteristic of substantially increased bone marrow cavity was only observed in the metaphyseal region. This effect may be predominantly associated with decreased number of trabeculae and increased spacing, since trabecular thickness was similar between the genotypes. Furthermore, trabecular degradation of sickle bone with respect to age was drastically more apparent in the metaphysis than the epiphysis, potentially due to an increased risk of vaso-occlusion derived from the more abundant and independent vasculature of the metaphysis [Lewis, 1956]. SMI provided further insight into 
the morphological differences of the trabecular structures across the genotypes and ages.

Trabecular bone is expected to transition from more plate-like to more rod-like architecture as age-related bone loss and remodeling occurs [Hildebrand and Rüegsegger, 1997]. However, sickle bone in the older animals had significantly more rod-like morphology than trait and wildtype animals, suggesting accelerated age-related structural changes.

Altogether, even small alterations in the trabecular and cortical microarchitecture and reduction in bone volume observed in trait and sickle bone may have contributed to differences in mechanical properties, especially for older animals. Interestingly, AS and SS bone exhibited opposing material behaviors; the former tended to be more rigid while SS bone expressed a more flexible nature than both AA and AS. Additionally, increased flexibility of the diseased genotype in combination with the maintenance of TMD and significantly lower elastic modulus suggest that there may be differences in the material composition of sickle bone.

Although it is largely accepted that sickling within the bone microcirculation is the most common cause of ischemia, thrombosis, and necrosis within bone, the exact pathophysiology of the phenomenon has yet to be further elucidated [Almeida and Roberts, 2005; Sarrai et al., 2007]. Recent studies have suggested that environmental cues, such as inflammatory molecules, may directly and/or indirectly influence the osteoporotic-like phenotype observed in bone [Baldwin et al., 2005; Séguin et al., 2008]. As a consequence of sickle erythrocyte and vascular endothelium interactions, sickle patients are known to have abnormally high concentrations of inflammatory proteins in comparison to non-sickle individuals [Kaul et al., 2009; Qari et al., 2012]. Specifically, interleukin (IL)-6 and IL-8 are elevated in SCD patients and have been associated with the up regulation and anti-apoptotic maintenance of osteoclast activity by increasing the expression of receptor activator of nuclear factor kappa- $\beta$ ligand (RANKL) 
[Nouraie et al., 2011]. Our preliminary studies also suggest that homeostatic coordination of bone remodeling signals in sickle bone is biased towards absorption due to reduced expression of osteoprotegerin (OPG) [unpublished]. Another inflammatory signal that has increased levels in $\mathrm{SCD}$, tumor necrosis factor (TNF)- $\alpha$, is thought to promote osteoclast differentiation independent of the RANKL mechanism when coupled with macrophage-colony stimulating factor [Kobayashi et al., 2000]. TNF- $\alpha$ also increases vascular endothelial expression of cathepsin K, the same collagenase used by osteoclasts during remodeling, suggesting the microvasculature itself as a potential accomplice in sickle bone deterioration [Keegan et al., 2012]. Under healthy conditions, inflammation plays a crucial role in regulating bone remodeling. However, the chronic inflammation localized within the bone microcirculation due to frequent sickle erythrocyte and vascular endothelium interactions may prolong osteoclast activity [Hardy and Cooper, 2009].

Apart from inflammation, clinicians have been investigating the negative impact of blood transfusions in patients with hematological disorders. For instance, Tsay et al. report that iron overload due to chronic transfusions exacerbates bone resorption and alteration of the trabecular microarchitecture in SCD patients [Tsay et al., 2010]; however, it has also been reported that both transfused and non-transfused sickle patients have the same risk of fracture [Fung et al., 2008a]. Recently, studies have also examined the impact of single nucleotide polymorphism mutations found in sickle patients suffering from osteonecrosis in genes other than the hemoglobin mutation [Baldwin et al., 2005]. The genes identified were associated with regulatory roles of parathyroid hormone and vitamin D in bone morphology, metabolism, and development. Additionally, sickle patients with a history of multiple fractures have been diagnosed with moderate to severe deficiency in vitamin $\mathrm{D}$, a key player in regulating osteoclast 
mediated bone resorption to release calcium, resulting in defective bone mineralization, or osteomalacia [Arlet et al., 2013]. Administration of supplemental vitamin D to sickle patients elevated their serum levels to the normal range and lead to slight improvement in BMD, but markers of bone resorption remain unaltered suggesting abnormal bone remodeling in SCD [Adewoye et al., 2008].

Collectively, mineralization and the architecture of the various bone regions establish a compensatory and dependent relationship to maintain essential mechanical functionality [Tommasini et al., 2008]. Unfortunately, SCD serves as an intricate auxiliary condition to aging that produces unique whole bone phenotypes and behaviors. Overall, young sickle bone may exhibit relatively normal attributes of mineral content as well as cortical and metaphyseal trabecular bone; however, with aging the combined effect of vaso-occlusion and intrinsic factors alter the bone microarchitectural morphology resulting in abnormally flexible yet functioning sickle bone. The decrease in the amount of force required to deform sickle mouse femurs compared to wild-type and trait may be indicative of the self-reported low impact fracture incidences in both children and adults, implying that SCD results in chronic pathological fracturing [Arlet et al., 2013; Fung et al., 2008a; Omer et al., 2013]. Clinical observations have illustrated that SCD patients are prone to have more bone deformities than fractures, thus supporting the malleability observed from the sickle and trait femurs [communication with Ifeyinwa Osunkwo, M.D.]. It may be that with age, SCD augments the natural degradation of the tissue microarchitecture, resulting in a mechanically more inferior bone that is not comparable to its non-sickle peers. Further examination of the influence of SCD on bone microvasculature and biomechanics related to the material properties will advance our understanding of sickle bone pathophysiology, leading to the development of more therapeutic approaches. 


\section{Acknowledgements}

This material is based upon work supported by the NIH AG027249, NIH 1DP2OD007433-01, HL 106192, HL 117721, and NSF GRFP DGE-1148903.

\section{$\underline{\text { References }}$}

Aaron, J. E., et al. 1987. The microanatomy of trabecular bone loss in normal aging men and women. Clinical Orthopedics. 215:260 -271.

Adewoye, A., et al. 2008. Sickle cell bone disease: Response to vitamin D and calcium. American Journal of Hematology. 83:271-274.

Aguilar, C., et al. 2005. Bone and joint disease in sickle cell disease. Hematology/Oncology Clinics of North America. (19) 929-941.

Almedia, A., and Roberts, I. 2005. Bone involvement in sickle cell disease. British Journal of Haematology. 129, 482-490.

Arlet, J., et al. 2013. Relationship between vitamin D deficiency and bone fragility in sickle cell disease: A cohort study adults. Bone. 52: 206-211.

Baldwin, C., et al. 2005. Association of klotho, bone morphogenic protein 6, and annexin A2 polymorphisms with sickle cell osteonecrosis. Blood. 106: 372-375.

Bonnet, N., et al. 2006. Severe bone alterations under $\beta 2$ agonist treatments: bone mass, microarchitecture and strength analyses in female rats. Bone. 37: 622-633.

Bouxsein, M. L., et al. 2010. Guidelines for assessment of bone microstructure in rodent using micro-computed tomography. Journal of Bone and Mineral Research. 25 (7): 1468-1486.

Brinker, M. R., et al. 1998. Bone mineral density of the lumbar spine and proximal femur is decreased in children with sickle cell anemia. American Journal of Orthopedics. 27(1): 43-49. 
Brodt, M.D., et al. 1999. Growing C57BL/6 mice increase whole bone mechanical properties by increasing geometric and material properties. Journal of Bone and Mineral Research. 14 (12): 2159-2166.

Buie, H. R., et al. 2007. Automatic segmentation of cortical and trabecular compartments based on a dual threshold technique for in vivo micro-CT bone analysis. Bone. 4:505-15.

Buison, A., et al. 2005. Bone area and bone mineral density content deficits in children with sickle cell disease. Pediatrics. 116 (4): 943-949.

Burstein, A.H., et al. 1975. Contribution of collagen and mineral to the elastic-plastic properties of bone. Journal of Bone and Joint Surgery.57: 956-961.

Carter, D.R., and Hayes, W.C. 1977. The compressive behavior of bone as a two-phase porous structure. Journal of Bone and Joint Surgery. 59: 954-962.

Chiang, E., and Frenette, P., 2005. Sickle cell vaso-occlusion. Hematology Oncology Clinical North American. 19(5), 771-784.

Ebong, W.W. 1986. Pathological fracture complicating long bone osteomyelitis in patients with sickle cell disease. Journal of Pediatric Orthopedics. 6: 177-181.

Ejindu, V., et al. 2007. Musculoskeletal manifestations of sickle cell disease. RadioGraphics. 27, 1005-1021.

Fung, E., et al. 2008. Fracture prevalence and relationship to endocrinopathy in iron overloaded patients with sickle cell disease and thalassemia. Bone. 43: 362-368.

Fung, E., et al. 2008. Markers of bone turnover are associated with growth and development in young subjects with sickle cell anemia. Pediatric Blood Cancer. 50(3):620-3. 
Gafni, R., and Baron, J. 2004. Overdiagnosis of osteoporosis in children due to misinterpretation of dual-energy x-ray absorptiometry (DEXA). The Journal of Pediatrics. 144(2): 253257.

Galante, J. et al. 1970. Physical properties of trabecular bone. Calcified Tissue Research. 5 (1): 236-246.

Ghosh, S., et al. 2012. Spatiotemporal dysfunction of the vascular permeability barrier in transgenic mice with sickle cell disease. Anemia. 2012: 1-6

Gibson, L. 1985. The Mechanical Behavior of cancellous bone. Journal of Biomechanical. 18: $317-328$.

Gupta, R., et al. 2009. Pattern of bone mineral density in sickle cell disease patients with high hB phenotype. Acta Haematologica. 123: 64-70.

Hardy, R., and Cooper, M.S. 2009. Bone loss in inflammatory disorders. Journal of Endocrinology. 201: 309-320.

Hildebrand, T., and Ruegsegger, P. 1997. Quantification of bone microarchitecture with the structure model index. Computational Methods Biomechanical Biomedical Engineering. 1:15-23.

Kaul, D., et al. 2009. Sickle cell with endothelium interactions. Microcirculation. 16(1): 97-111.

Keegan, P., et al. 2012. Sickle cell disease activates peripheral blood mononuclear cells to induce cathepsins $\mathrm{K}$ and $\mathrm{V}$ activity in endothelial cells. Anemia. 1-7.

Kobayashi, K., et al. 2000. Tumor necrosis factor $\alpha$ stimulates osteoclast differentiation by a mechanism independent of the ODF/RANKL-RANK interaction. J. Exp. Med. 191 (2: $275-285$. 
Lal, A., et al. 2006. Bone mineral density in children with sickle cell anemia. Pediatric Blood and Cancer. 47 (7): 901-906.

Laroche, M., et al. 1998. Dual-energy X-ray absorptiometry in osteonecrosis of the femoral head. Revue du Rhumatisme English Edition. 65(6): 393-396.

Lewis, O.J. 1956. The blood supply of developing long bones with special reference to the metaphyses. Journal of Bone and Joint Surgery. 38: 9258-933.

Miller, R.G., et al. 2006. High prevalence and correlates of low bone mineral density in young adults with sickle cell disease. American Journal of Hematology. 81(4):236-241.

Milner, P., et al. 1991. Sickle cell disease as a cause of osteonecrosis of the femoral head. New England Journal of Medicine. 325(21):1476-1481.

Nouraie, M., et al. 2011. Predictors of osteoclast activity in patients with sickle cell disease. Haemotologica. 96 (8): 1092-98.

Omer, N.E., et al. 2013. Multiple pathologic fractures in a 19-month-old boy with sickle cell disease. Grand Rounds. 13: 63-68.

Qari, M., Dier, U., and Mousa, S. 2012. Biomarkers of inflammation, growth factor, and coagulation activation in patients with sickle cell disease. Clinical and Applied Thrombosis/Hemostasis. 18:195-200.

Rao, V., et al. 1989. Marrow infarction in sickle cell anemia: correlation with marrow type and distribution by MRI. Magnetic Resonance Imaging. 7(1):39-44.

Reprinted from Bone, 39/4, Robertson, G., et al., Alteration of femoral bone morphology and density in COX-2-/- mice, 767-772, (2006), with permission from Elsevier.

Robertson, G., et al. 2006. Alteration of femoral bone morphology and density in COX-2-/mice. Bone. 39(4): 767-772. 
Ryan, T., et al. 1997. Knockout-Transgenic Mouse Model of Sickle Cell Disease. Science. 278: 873-875.

Sarrai, M., et al. 2007. Bone mass density in adults with sickle cell disease. British Journal of Haematology. 136(4): 666-672.

Sartoris, D.J., and Resnick, D. 1988. Dual-energy radiographic absorptiometry for bone densitometry: current status and perspective. American Roentgen Society. 152: 241-246.

Séguin, C., et al. 2008. Non-traumatic necrosis of bone (osteonecrosis) is associated with endothelial cell activation but not thrombophilia. Rheumatology. 47: 1151-1155.

Serjeant, G., Serjeant B. 2001. Bone and joint lesions, in: Sickle Cell Disease. Oxford University Press, New York, pp. 240-280.

Smith, J., 1996. Bone disorders in sickle cell disease. Hematology/Oncology Clinics of North America. 10(6): 1345- 1356.

Stenström, M., et al. 2000. Bone mineral density and bone structure parameters as predictors of bone strength: an analysis using computerized microtomography and gastrectomyinduced osteopenia in the rat. Journal of Biomechanics. 33: 289-297.

Tommasini, S.M., et al. 2008. Biological co-adaptation of morphological and composition traits contributes to mechanical functionality and skeletal fragility. Journal of Bone and Mineral Research. 23 (2): 236-246.

Tsay, J., et al. 2010. Bone loss caused by iron overload in a murine model: importance of oxidative stress. Blood. 116: 2592-2589.

Turner, C.H., and Burr, D.B. 1993. Basic biomechanical measurements of bone: a tutorial. Bone. 14: 595-608. 
Turner, C.H., et al. 1990. The fabric dependence of the orthotropic elastic constants of cancellous bone. Journal of Biomechanics. 23: 549-561.

Ulrich, D., et al. 1997. The quality of trabecular bone evaluated with micro-computed tomography, FEA and mechanical testing. Studies in Health Technology Informatics. 40: $97-112$.

Mankad, V.N., et al., 1990. Magnetic resonance imaging of bone marrow in sickle cell disease: clinical, hematologic, and pathologic correlations. Blood. 75(1): 274-283.

Wang, G., et al. 2005. Design, analysis and simulation for the development of the first clinical micro-CT scanner. Acad Radiol. 12: 511-525.

Ware, H.E., et al. 1991. Sickle cell disease and silent avascular necrosis of the hip. The Bone and Joint Journal. 73: 947-949.

World Health Organization. 1994. Assessment of fracture risk and its application to screening for postmenopausal osteoporosis report of a WHO study group, first ed. World Health Organization, Geneva.

Wren, T., et al. 2005. Bone densitometry in pediatric populations: discrepancies in the diagnosis of osteoporosis by DXA and CT. The Journal of Pediatrics. 146(6): 776-779. 


\section{Figures}

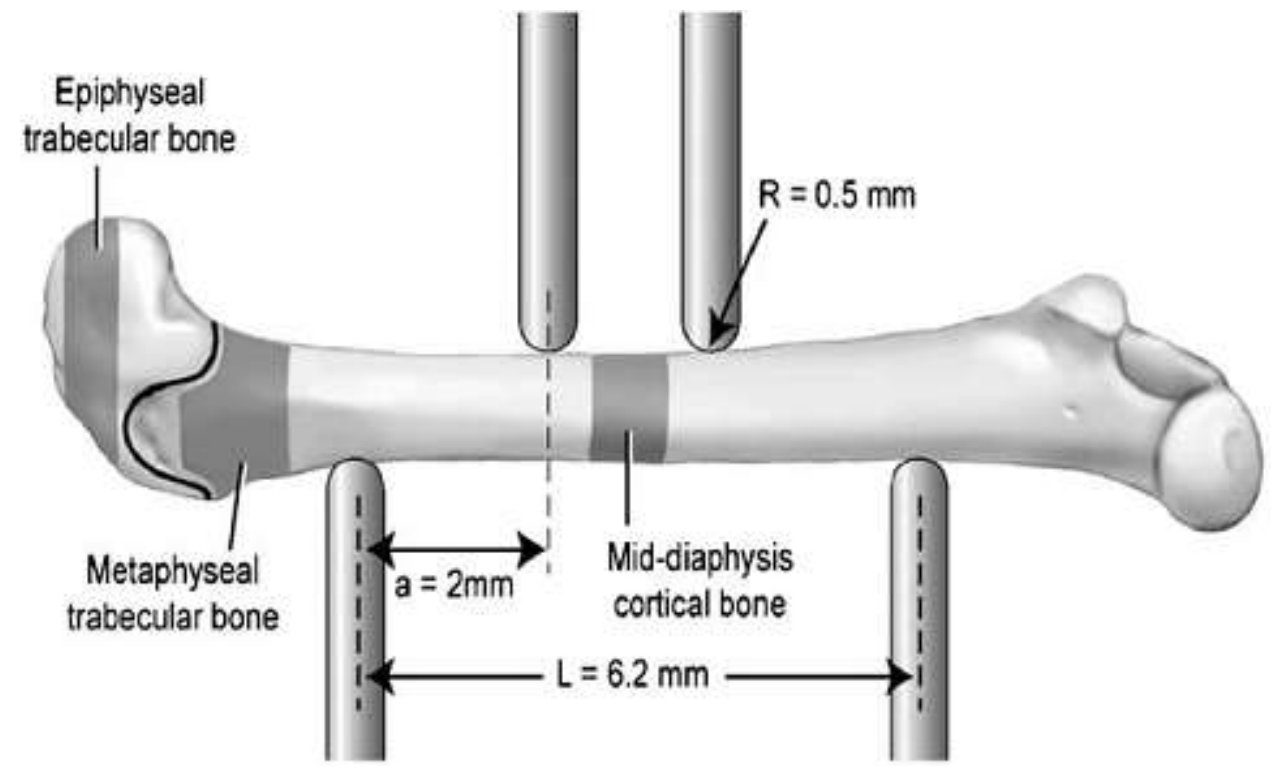

Fig. 1 - Schematic setup of four point bending and femur placement. The regions of interest that were scanned and analyzed by micro-CT for morphological assessment are highlighted. Location of growth plate between trabecular regions is represented as a black line. The distance between the two upper points is $2.2 \mathrm{~mm}$ (not shown). [Reprinted from Bone, 39/4]. One Column 


\begin{tabular}{|c|c|c|c|c|c|c|}
\hline \multirow[t]{2}{*}{$\mathrm{BMD}\left(\mathrm{mg} \mathrm{HA} / \mathrm{cm}^{3}\right)$} & \multicolumn{3}{|c|}{10 Weeks } & \multicolumn{3}{|c|}{21 Weeks } \\
\hline & $\overline{\mathbf{A A}}$ & $\mathbf{A S}$ & SS & $\overline{\mathbf{A A}}$ & $\mathbf{A S}$ & SS \\
\hline Epiphysis & $\begin{array}{c}1049.2 \\
(0.29)\end{array}$ & $\begin{array}{l}1101.1 \\
(28.04)\end{array}$ & $\begin{array}{l}1083.6 \\
(19.03)\end{array}$ & $\begin{array}{l}1151.6 \\
(12.67)\end{array}$ & $\begin{array}{c}1184.2 \\
(7.59)\end{array}$ & $\begin{array}{c}1161.9 \\
(13.1)\end{array}$ \\
\hline Metaphysis & $\begin{array}{c}1008.9 \\
(8.4)\end{array}$ & $\begin{array}{c}1053.1 \\
(34.79)\end{array}$ & $\begin{array}{l}1070.4 \\
(46.17)\end{array}$ & $\begin{array}{l}1104.2 \\
(21.72)\end{array}$ & $\begin{array}{c}1144.9 \\
(0.07)\end{array}$ & $\begin{array}{l}1117.5 \\
(4.97)\end{array}$ \\
\hline Mid-Diaphysis & $\begin{array}{l}1369.4 \\
(63.61)\end{array}$ & $\begin{array}{c}1428.5 \\
(4.24)\end{array}$ & $\begin{array}{l}1396.3 \\
(13.21)\end{array}$ & $\begin{array}{c}1452.6 \\
(12.68)\end{array}$ & $\begin{array}{c}1534.1 \\
(5.71)\end{array}$ & $\begin{array}{l}1467.8 \\
(11.76)\end{array}$ \\
\hline
\end{tabular}

Table 1 - Femoral bone mineral density levels in 10- and 21-week old sickle cell (SS) mice and control littermates with sickle cell trait (AS), and normal human hemoglobin (AA).Data are presented as mean (SEM). Half-page

10 Weeks

Mid-Diaphysis

Cort. Th.

\begin{tabular}{ccc} 
AA & AS & SS \\
\hline \hline 0.182 & 0.18 & $0.145^{\mathrm{ac}}$
\end{tabular}

$(0.021)$

(0.004)

(0.004)

0.155

(0.021)

0.134

(0.005)

0.122

(0.004)

BA $\left(\mathrm{mm}^{2}\right)$

0.877

(0.085)

0.802

(0.027)

$0.658^{\mathrm{a}}$

(0.123)

$\mathrm{TA}\left(\mathrm{mm}^{2}\right)$

$$
2.046
$$$$
1.875
$$$$
1.901
$$$$
\text { (0.071) }
$$

(0.078)

\begin{tabular}{ccc}
\multicolumn{3}{c}{ 21 Weeks } \\
AA & AS & SS \\
\hline \hline 0.197 & 0.18 & $0.139^{\mathrm{ac}}$ \\
$(0.004)$ & $(0.009)$ & $(0.006)$ \\
0.17 & 0.124 & 0.153 \\
$(0.0051)$ & $(0.012)$ & $(0.01)$ \\
0.927 & $0.757^{\mathrm{b}}$ & $0.675^{\mathrm{a}}$ \\
$(0.035)$ & $(0.055)$ & $(0.168)$ \\
2.131 & 1.732 & $2.123^{\mathrm{d}}$ \\
$(0.136)$ & $(0.108)$ & $(0.037)$
\end{tabular}

Table 2 - Cortical bone morphological and geometric data generated from micro-CT image analysis. Data are presented as mean (SEM). Half-page

${ }^{a}$ Significance between wild-type and sickle $(P<0.05)$.

${ }^{b}$ Significance between wild-type and trait $(P<0.05)$

${ }^{c}$ Significance between trait and sickle $(\mathrm{P}<0.05)$

${ }^{\mathrm{d}}$ Significance between age within genotype $(\mathbf{P}<0.05)$ 

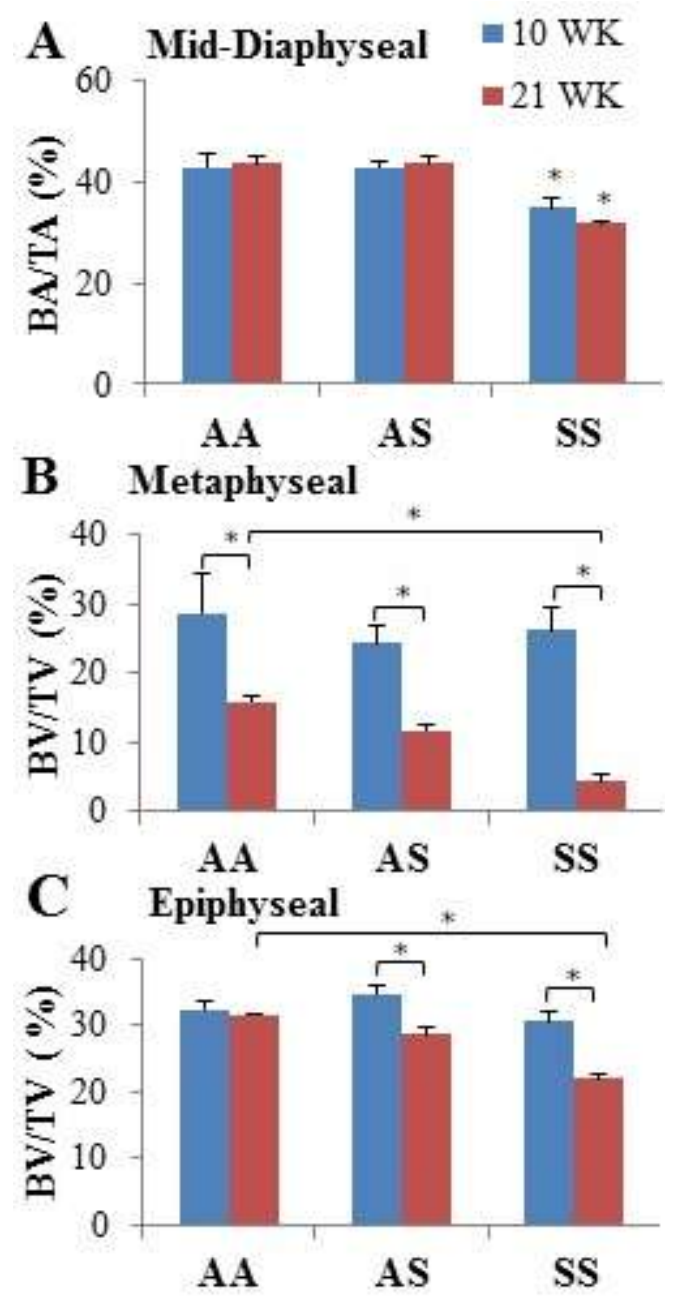

Fig. 2 - Micro-CT measured area and volume occupied by mineralized tissue within cortical (mid-diaphyseal) and trabecular (metaphyseal and epiphyseal) bone respectively at the ages of 10 and 21 weeks. Data shown represent mean \pm SEM. * indicates significance $(P$ $<0.05)$. One-column 

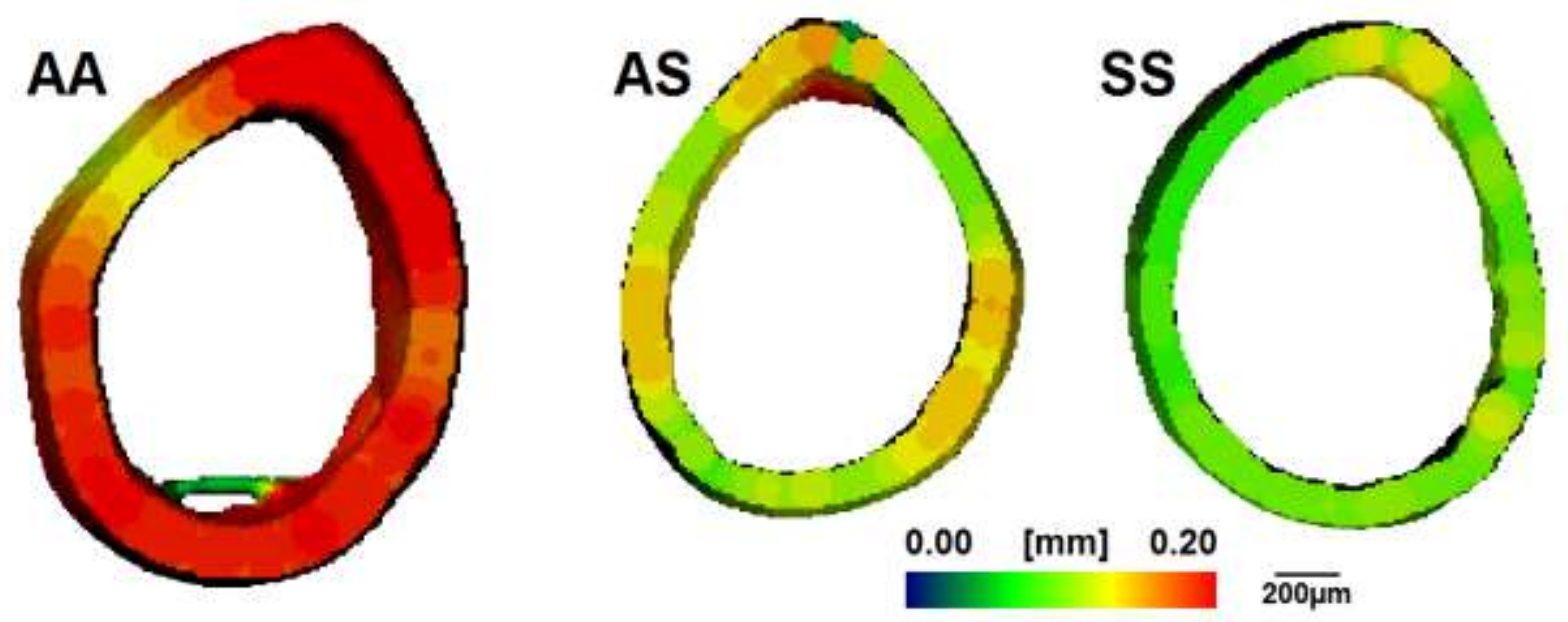

Fig. 3 - Micro-CT generated representative 3D heat maps of AA, AS, and SS femoral middiaphyseal cortical thickness of at 21 weeks of age. Thickness is depicted in pseudocolor scale, red $(0.2 \mathrm{~mm})$ to blue $(0 \mathrm{~mm})$. Scale bar equals $200 \mu \mathrm{m}$. Full-page 


\begin{tabular}{|c|c|c|c|c|c|c|}
\hline \multirow[b]{2}{*}{ Epiphysis } & \multicolumn{3}{|c|}{10 Weeks } & \multicolumn{3}{|c|}{21 Weeks } \\
\hline & $\mathbf{A A}$ & AS & SS & $\mathbf{A A}$ & AS & SS \\
\hline $\begin{array}{l}\text { Tb. N. } \\
(1 / \mathrm{mm})\end{array}$ & $\begin{array}{c}8.725 \\
(0.466)\end{array}$ & $\begin{array}{c}8.68 \\
(0.226)\end{array}$ & $\begin{array}{c}8.687 \\
(0.036)\end{array}$ & $\begin{array}{c}8.094 \\
(0.049)\end{array}$ & $\begin{array}{c}8.058 \\
(0.054)\end{array}$ & $\begin{array}{c}8.015 \\
(0.012)\end{array}$ \\
\hline $\begin{array}{l}\text { Tb. Th. } \\
\text { (mm) }\end{array}$ & $\begin{array}{c}0.054 \\
(0.001)\end{array}$ & $\begin{array}{c}0.055 \\
(0.001)\end{array}$ & $\begin{array}{c}0.051 \\
(0.002)\end{array}$ & $\begin{array}{c}0.055 \\
(0.0004)\end{array}$ & $\begin{array}{c}0.053 \\
(0.001)\end{array}$ & $\begin{array}{c}0.047^{\mathrm{a}} \\
(0.001)\end{array}$ \\
\hline $\begin{array}{l}\text { Conn.D. } \\
\left(1 / \mathrm{mm}^{3}\right)\end{array}$ & $\begin{array}{c}284.963 \\
(9.315)\end{array}$ & $\begin{array}{l}270.122 \\
(19.998)\end{array}$ & $\begin{array}{l}320.402 \\
(32.517)\end{array}$ & $\begin{array}{c}207.917^{\mathrm{d}} \\
(4.716)\end{array}$ & $\begin{array}{c}210.862^{\mathrm{d}} \\
(8.478)\end{array}$ & $\begin{array}{c}222.695^{\mathrm{d}} \\
(16.21)\end{array}$ \\
\hline $\begin{array}{l}\text { Tb. Sp. } \\
(\mathrm{mm})\end{array}$ & $\begin{array}{c}0.125 \\
(0.003)\end{array}$ & $\begin{array}{c}0.117 \\
(0.001)\end{array}$ & $\begin{array}{c}0.12 \\
(0.002)\end{array}$ & $\begin{array}{c}0.129 \\
(0.001)\end{array}$ & $\begin{array}{c}0.131 \\
(0.002)\end{array}$ & $\begin{array}{c}0.132 \\
(0.003)\end{array}$ \\
\hline SMI & $\begin{array}{l}0.418 \\
(0.16)\end{array}$ & $\begin{array}{c}0.304 \\
(0.238)\end{array}$ & $\begin{array}{c}0.85 \\
(0.27)\end{array}$ & $\begin{array}{c}0.356 \\
(0.027)\end{array}$ & $\begin{array}{c}0.577 \\
(0.079)\end{array}$ & $\begin{array}{l}1.121^{\mathrm{d}} \\
(0.087)\end{array}$ \\
\hline $\mathrm{TV}\left(\mathrm{mm}^{3}\right)$ & $\begin{array}{c}0.558 \\
(0.014)\end{array}$ & $\begin{array}{c}0.589 \\
(0.046)\end{array}$ & $\begin{array}{c}0.589 \\
(0.011)\end{array}$ & $\begin{array}{c}0.572 \\
(0.005)\end{array}$ & $\begin{array}{c}0.574 \\
(0.004)\end{array}$ & $\begin{array}{c}0.639 \\
(0.019)\end{array}$ \\
\hline $\mathrm{BV}\left(\mathrm{mm}^{3}\right)$ & $\begin{array}{c}0.181 \\
(0.015)\end{array}$ & $\begin{array}{c}0.201 \\
(0.008)\end{array}$ & $\begin{array}{c}0.179 \\
(0.019)\end{array}$ & $\begin{array}{c}0.179 \\
(0.003)\end{array}$ & $\begin{array}{c}0.163 \\
(0.006)\end{array}$ & $\begin{array}{c}0.139 \\
(0.001)\end{array}$ \\
\hline Metaphysis & $\mathbf{A A}$ & AS & SS & $\mathbf{A A}$ & $\mathbf{A S}$ & SS \\
\hline $\begin{array}{l}\text { Tb. N. } \\
(1 / \mathrm{mm})\end{array}$ & $\begin{array}{c}7.072 \\
(0.324)\end{array}$ & $\begin{array}{c}7.011 \\
(0.261)\end{array}$ & $\begin{array}{l}7.143 \\
(0.13)\end{array}$ & $\begin{array}{c}5.064^{\mathrm{d}} \\
(0.137)\end{array}$ & $\begin{array}{l}4.275^{\mathrm{ad}} \\
(0.242)\end{array}$ & $\begin{array}{l}3.393^{\mathrm{ad}} \\
(0.415)\end{array}$ \\
\hline $\begin{array}{l}\text { Tb. Th. } \\
\text { (mm) }\end{array}$ & $\begin{array}{c}0.058 \\
(0.008)\end{array}$ & $\begin{array}{c}0.051 \\
(0.002)\end{array}$ & $\begin{array}{c}0.052 \\
(0.004)\end{array}$ & $\begin{array}{c}0.05 \\
(0.001)\end{array}$ & $\begin{array}{c}0.048 \\
(0.002)\end{array}$ & $\begin{array}{c}0.037 \\
(0.005)\end{array}$ \\
\hline $\begin{array}{l}\text { Conn.D. } \\
\left(1 / \mathrm{mm}^{3}\right)\end{array}$ & $\begin{array}{c}274.196 \\
(0.475)\end{array}$ & $\begin{array}{l}308.618 \\
(23.524)\end{array}$ & $\begin{array}{l}314.778 \\
(11.519)\end{array}$ & $\begin{array}{c}139.526^{\mathrm{d}} \\
(9.219)\end{array}$ & $\begin{array}{c}95.544^{\mathrm{bd}} \\
(9.819)\end{array}$ & $\begin{array}{c}26.649^{\mathrm{ad}} \\
(9.15)\end{array}$ \\
\hline $\begin{array}{l}\text { Tb. Sp. } \\
\text { (mm) }\end{array}$ & $\begin{array}{c}0.131 \\
(0.009)\end{array}$ & $\begin{array}{c}0.138 \\
(0.008)\end{array}$ & $\begin{array}{c}0.131 \\
(0.005)\end{array}$ & $\begin{array}{c}0.202^{\mathrm{d}} \\
(0.005)\end{array}$ & $\begin{array}{l}0.243^{\mathrm{bd}} \\
(0.014)\end{array}$ & $\begin{array}{c}0.302^{\mathrm{acd}} \\
(0.034)\end{array}$ \\
\hline SMI & $\begin{array}{c}1.155 \\
(0.507)\end{array}$ & $\begin{array}{c}1.657 \\
(0.211)\end{array}$ & $\begin{array}{c}1.583 \\
(0.254)\end{array}$ & $\begin{array}{c}2.028 \\
(0.078)\end{array}$ & $\begin{array}{c}2.344 \\
(0.135)\end{array}$ & $\begin{array}{l}3.069^{\mathrm{acd}} \\
(0.325)\end{array}$ \\
\hline $\mathrm{TV}\left(\mathrm{mm}^{3}\right)$ & $\begin{array}{c}1.216 \\
(0.051)\end{array}$ & $\begin{array}{c}1.35 \\
(0.046)\end{array}$ & $\begin{array}{l}1.245 \\
(0.03)\end{array}$ & $\begin{array}{c}1.389 \\
(0.021)\end{array}$ & $\begin{array}{c}1.373 \\
(0.071)\end{array}$ & $\begin{array}{c}1.556^{\mathrm{d}} \\
(0.167)\end{array}$ \\
\hline $\mathrm{BV}\left(\mathrm{mm}^{3}\right)$ & $\begin{array}{c}0.355 \\
(0.867)\end{array}$ & $\begin{array}{c}0.325 \\
(0.031)\end{array}$ & $\begin{array}{c}0.324 \\
(0.041)\end{array}$ & $\begin{array}{l}0.171 \\
(0.11)\end{array}$ & $\begin{array}{c}0.156^{\mathrm{d}} \\
(0.013)\end{array}$ & $\begin{array}{l}0.066^{\mathrm{ad}} \\
(0.014)\end{array}$ \\
\hline
\end{tabular}

Table 3 - Femoral trabecular micro-architecture in 10- and 21-week wild-type, trait, and sickle mice. Data are presented as mean (SEM). Full page

${ }^{a}$ Significance between wild-type and sickle $(\mathrm{P}<0.05)$.

${ }^{\mathrm{b}}$ Significance between wild-type and trait $(\mathbf{P}<0.05)$ 
${ }^{\mathrm{c}}$ Significance between trait and sickle $(\mathrm{P}<0.05)$

${ }^{\mathrm{d}}$ Significance between age within genotype $(\mathbf{P}<\mathbf{0 . 0 5})$ 

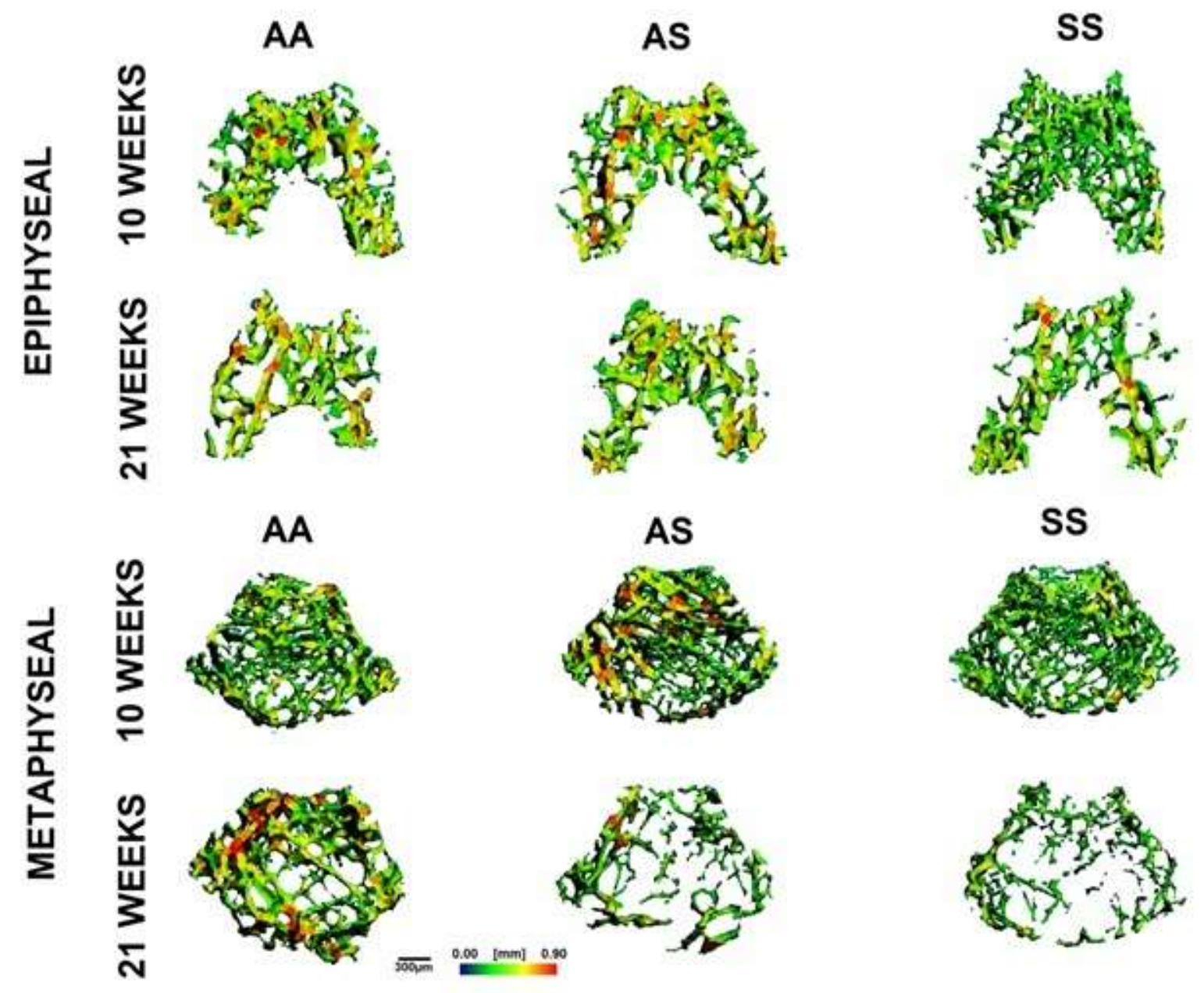

Fig. 4 - Micro-CT generated representative 3D map of epiphyseal (top) and metaphyseal (bottom) trabecular morphology with respect to genotype and age. Measurements are depicted in color scale, red $(0.09 \mathrm{~mm})$ to blue $(0 \mathrm{~mm})$. Scale bar equals $300 \mu \mathrm{m}$.

Full Page 


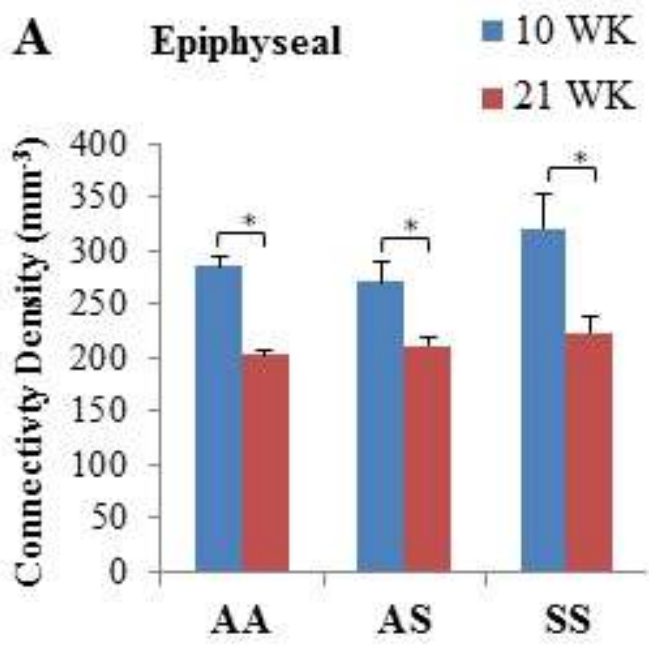

B Metaphyseal

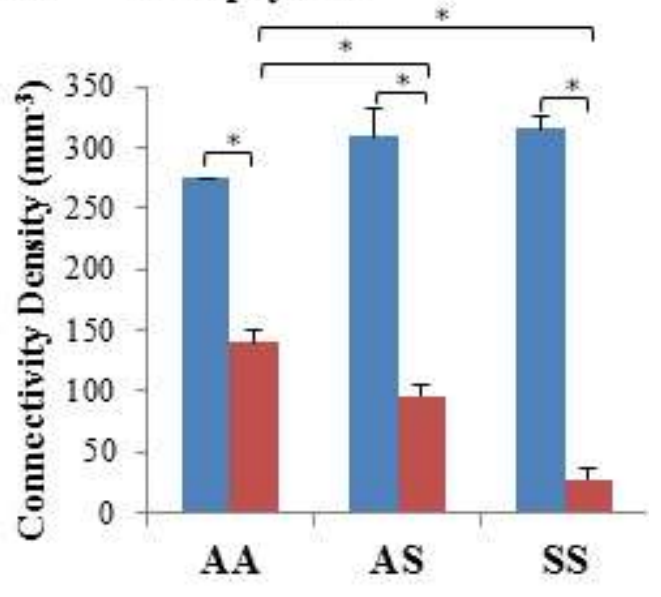

Fig. 5 - Epiphyseal and metaphyseal trabecular connectivity densities determined by microCT scans in AA, AS, and SS from 10- and 21-week old mice femurs. Data shown represent mean \pm SEM. * indicates significance $(P<0.05)$.

One column 


\begin{tabular}{|c|c|c|c|c|c|c|}
\hline & \multicolumn{3}{|c|}{10 Weeks } & \multicolumn{3}{|c|}{21 Weeks } \\
\hline & $\mathbf{A A}$ & $\mathbf{A S}$ & SS & $\mathbf{A A}$ & $\mathbf{A S}$ & SS \\
\hline $\begin{array}{l}\text { Stiffness } \\
(\mathrm{N} / \mathrm{mm})\end{array}$ & $\begin{array}{l}160.78 \\
(29.16)\end{array}$ & $\begin{array}{c}151.8 \\
(15.77)\end{array}$ & $\begin{array}{c}100.49^{\mathrm{ac}} \\
(5.51)\end{array}$ & $\begin{array}{l}168.22 \\
(12.69)\end{array}$ & $\begin{array}{c}155.67 \\
(18.4)\end{array}$ & $\begin{array}{c}120.12^{\mathrm{ac}} \\
(13.7)\end{array}$ \\
\hline $\begin{array}{l}\text { Post yield } \\
\text { Deflection } \\
\quad(\mathrm{mm})\end{array}$ & $\begin{array}{c}0.147 \\
(0.015)\end{array}$ & $\begin{array}{l}0.247^{b} \\
(0.042)\end{array}$ & $\begin{array}{c}0.299^{\mathrm{a}} \\
(0.002)\end{array}$ & $\begin{array}{c}0.218 \\
(0.041)\end{array}$ & $\begin{array}{c}0.279 \\
(0.024)\end{array}$ & $\begin{array}{c}0.239 \\
(0.085)\end{array}$ \\
\hline $\mathrm{E}(\mathrm{GPa})$ & $\begin{array}{c}3.62 \\
(0.33)\end{array}$ & $\begin{array}{c}4.05 \\
(0.43)\end{array}$ & $\begin{array}{c}2.93^{\mathrm{ac}} \\
(0.3)\end{array}$ & $\begin{array}{c}3.27 \\
(0.26)\end{array}$ & $\begin{array}{l}4.56^{\mathrm{b}} \\
(0.73)\end{array}$ & $\begin{array}{l}2.79^{\mathrm{ac}} \\
(0.28)\end{array}$ \\
\hline Work (Nmm) & $\begin{array}{l}5.13 \\
(1.48)\end{array}$ & $\begin{array}{c}6.48 \\
(1.85)\end{array}$ & $\begin{array}{l}5.19 \\
(0.2)\end{array}$ & $\begin{array}{c}5.02 \\
(1.35)\end{array}$ & $\begin{array}{c}5.92 \\
(0.43)\end{array}$ & $\begin{array}{c}4.48 \\
(0.73)\end{array}$ \\
\hline $\begin{array}{l}\text { Max Force } \\
(\mathrm{N})\end{array}$ & $\begin{array}{c}26.4 \\
(7.53)\end{array}$ & $\begin{array}{l}20.68 \\
(2.03)\end{array}$ & $\begin{array}{l}17.05 \\
(1.21)\end{array}$ & $\begin{array}{l}26.21 \\
(3.57)\end{array}$ & $\begin{array}{c}22.4 \\
(1.63)\end{array}$ & $\begin{array}{l}15.9^{\mathrm{ac}} \\
(1.16)\end{array}$ \\
\hline $\begin{array}{l}\text { Yield Force } \\
\qquad(\mathrm{N})\end{array}$ & $\begin{array}{l}19.12 \\
(4.95)\end{array}$ & $\begin{array}{c}8.74 \\
(1.01)\end{array}$ & $\begin{array}{l}10.71 \\
(0.12)\end{array}$ & $\begin{array}{l}12.56 \\
(0.81)\end{array}$ & $\begin{array}{l}12.79 \\
(2.8)\end{array}$ & $\begin{array}{l}7.29^{\mathrm{ad}} \\
(0.62)\end{array}$ \\
\hline $\begin{array}{c}\text { Ultimate } \\
\text { Stress (MPa) }\end{array}$ & $\begin{array}{l}114.96 \\
(23.14)\end{array}$ & $\begin{array}{c}103.75 \\
(8.67)\end{array}$ & $\begin{array}{l}96.09 \\
(8.75)\end{array}$ & $\begin{array}{l}116.85 \\
(15.19)\end{array}$ & $\begin{array}{c}119.61 \\
(5.32)\end{array}$ & $\begin{array}{c}78.39^{\mathrm{a}} \\
(10.72)\end{array}$ \\
\hline $\begin{array}{l}\text { Yield Stress } \\
\qquad(\mathrm{MPa})\end{array}$ & $\begin{array}{c}83.63 \\
(14.84)\end{array}$ & $\begin{array}{l}44.64 \\
(6.84)\end{array}$ & $\begin{array}{l}60.25 \\
(2.14)\end{array}$ & $\begin{array}{l}50.42 \\
(1.27)\end{array}$ & $\begin{array}{c}69.27 \\
(16.64)\end{array}$ & $\begin{array}{c}35.26^{\mathrm{ad}} \\
(1.27)\end{array}$ \\
\hline
\end{tabular}

Table 4 - Femoral mechanical properties generated by four point bending in 10- and 21weeks old wild-type (AA), trait (AS), and sickle (SS) mice. Data are presented as mean (SEM). Full page

${ }^{\text {a }}$ Significance between wild-type and sickle $(P<0.05)$.

${ }^{b}$ Significance between wild-type and trait $(P<0.05)$

${ }^{c}$ Significance between trait and sickle $(P<0.05)$

${ }^{\mathrm{d}}$ Significance between age within genotype $(\mathrm{P}<0.05)$ 

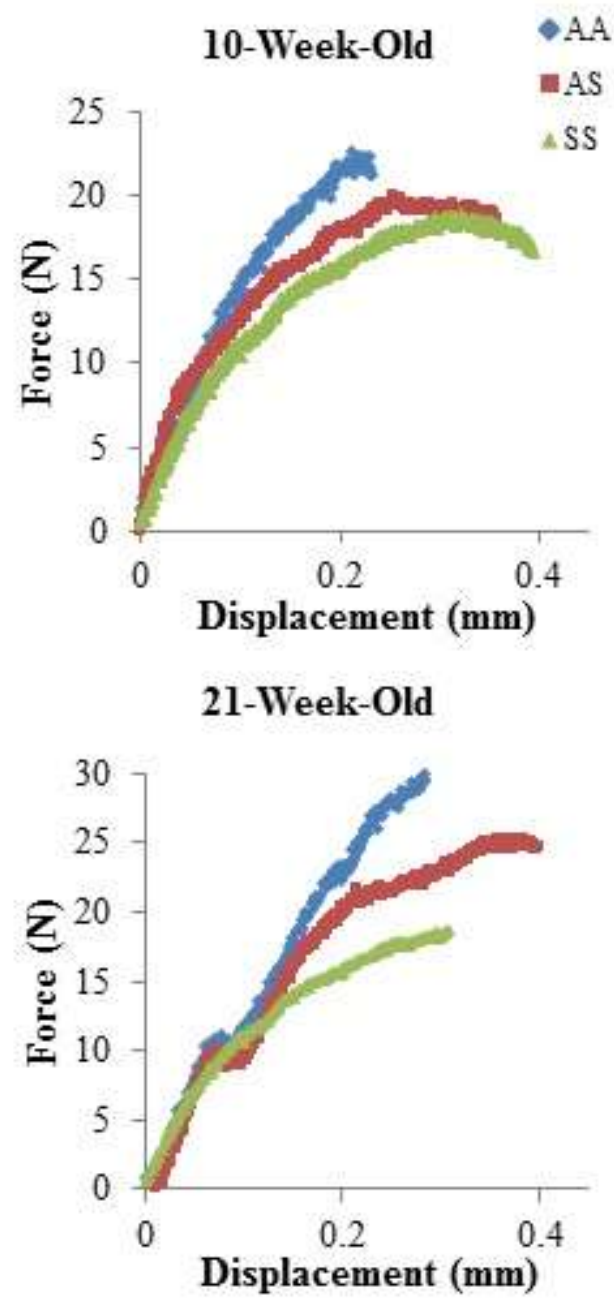

Fig. 6- Force-displacement curves representative of the mechanical behavior of AA, AS, and SS mice femurs at 10- and 21-weeks old as determined by four-point bending. One column 

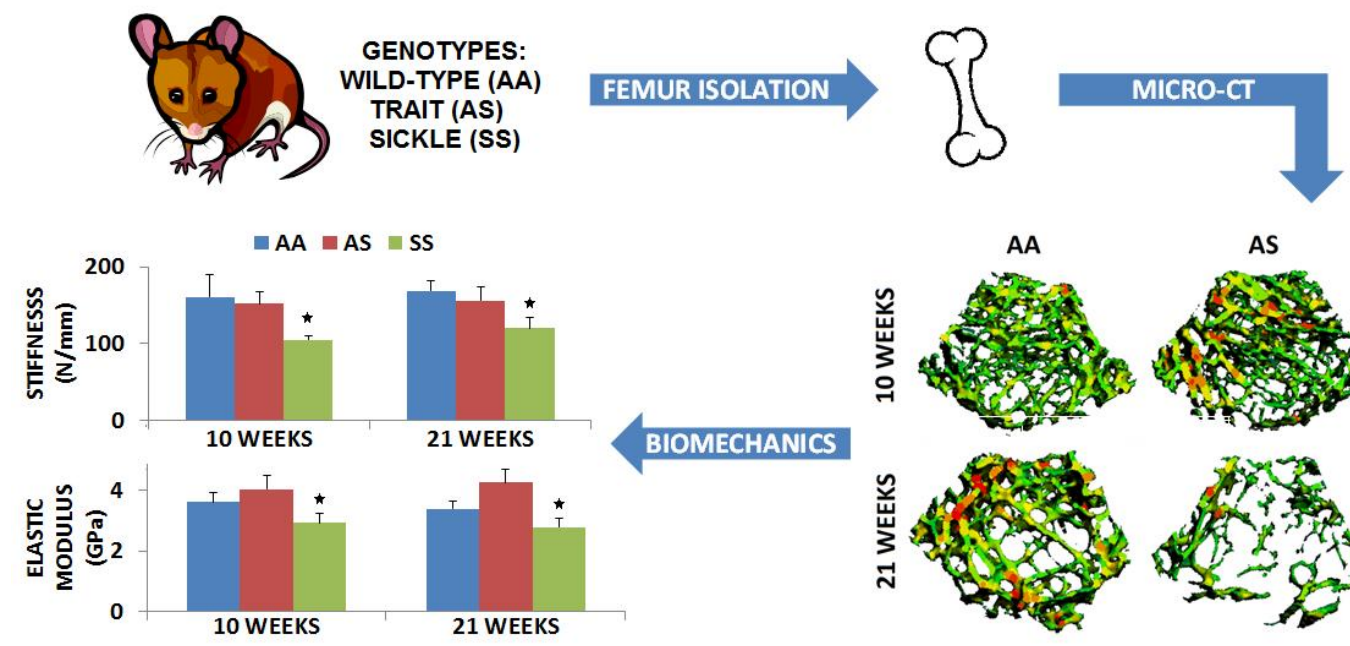

BIOMECHANICS
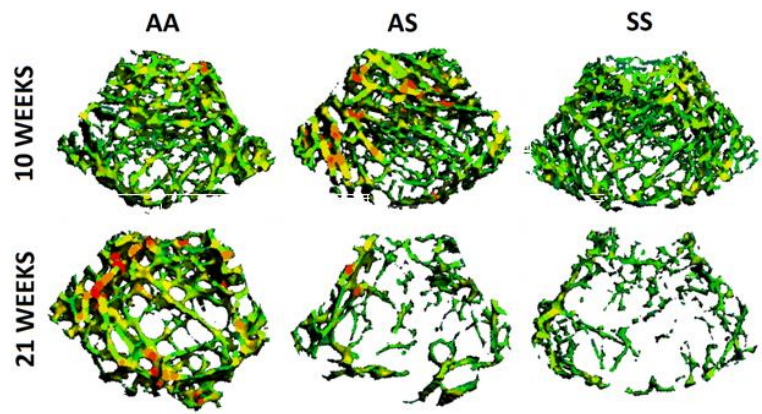